\title{
Mechanical characterization of integral aluminum-FRP-structures produced by high pressure die-casting
}

\author{
Jan Clausen $^{1} \cdot$ Milan Kelch $^{1,2} \cdot$ Franz-Josef Wöstmann ${ }^{1} \cdot$ Matthias Busse $^{1,3}$
}

Received: 30 November 2017 / Accepted: 16 February 2018 / Published online: 23 February 2018

(c) The Author(s) 2018. This article is an open access publication

\begin{abstract}
Due to the growing demand for light-weight solutions in a wide range of industrial sectors, the selection and combination of different materials is becoming more and more important. As a result, there is an increasing need for suitable joining technologies. In a new joining process, flexible glass fiber textiles are integrated into aluminum by high pressure die casting in the first production step. These structures are used for the electrochemical insulation between aluminum and carbon fiber textiles, which are connected in the subsequent production step by textile technology. The finished compound is formed in a final resin impregnation process. Challenges faced by Fraunhofer IFAM lie in the positioning, pre-tensioning, and infiltration of the glass fiber textiles in the high pressure die-casting process. The advantage of this joining technology, in addition to the electrochemical insulation between aluminum and carbon fibers, is in a slim and light-weight connection. Therefore, no thickening of the individual joining partners is necessary, and the force flow lines are not deflected. Within mechanical investigations of those hybrid structures it was determined, that the infiltration content of aluminum has only a small influence on the achievable tensile strength. Rather, casting parameters such as the holding pressure have an influence. The subsequent resin infusion process enables an additional infiltration by the resin system of fiber bundles that have been only slightly infiltrated with aluminum. As a result, additional adhesion can be achieved and the infiltration gaps can be closed. Furthermore, an influence on the achievable tensile strength was observed regarding the use of the fiber material. Further increases in tensile strengths were also observed by adapting the textile parameters (e.g. reduction of the fiber undulations). A variety of failure behaviors could be observed in dependence on textile and process parameters. Tensile strength of the hybrid structures was compared to reference samples made of glass fiber reinforced epoxy resin, to determine the loss of strength caused by the joining technology. Further investigations were carried out, including a fracture surface analysis using a scanning electron microscope. Thus it was possible to determine mechanisms of adhesion between encapsulated glass fibers and the surrounding aluminum matrix.
\end{abstract}

Keywords Hybrid · Composite · CFRP · Aluminum · High pressure die-casting · Tool design · Glass fiber · Joining technology $\cdot$ Lightweight materials $\cdot$ Transition structure $\cdot$ Multi-material

Jan Clausen

jan.clausen@ifam.fraunhofer.de

Milan Kelch

milan.kelch@hs-bremen.de

Franz-Josef Wöstmann

franz-josef.woestmann@ifam.fraunhofer.de

Matthias Busse

matthias.busse@ifam.fraunhofer.de

1 Fraunhofer Institute for Manufacturing and Advanced Materials IFAM, Wiener Str. 12, 28359 Bremen, Germany

2 Hochschule Bremen, The Biological Materials Group, Neustadtswall 30, 28199 Bremen, Germany

3 University of Bremen, Bibliothekstr. 1, 28359 Bremen, Germany

\section{Introduction}

In order to meet the increasing demand for load-balanced multi-material design, various innovative joining compounds between aluminum and carbon fiber reinforced polymers (CFRP) are currently under investigation. A promising approach is to partially integrate fiber structures into aluminum and infiltrate the fibers partially during the formation process of the aluminum part (e.g. casting, squeezing or forging) [1,2]. One of these approaches uses the aluminum high pressure die-casting; glass fibers act as a transitional structure between the aluminum and the CFRP part. Direct contact between the aluminum and the carbon fibers should 
Table 1 Compilation of the glass fiber textiles used for the experiments and their selected properties

\begin{tabular}{|c|c|c|c|c|c|}
\hline Description & 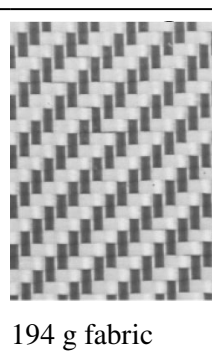 & $\mathrm{C}^{-1}$ & 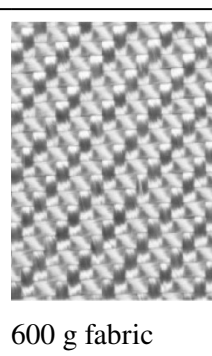 & $\frac{11}{1}$ & 1749 g laying \\
\hline Woven type & Fabric & Fabric & Fabric & Laying & Laying \\
\hline Fiber type & E-glass & E-glass & S-glass & E-glass & E-glass \\
\hline Grammage $\left(\mathrm{g} / \mathrm{m}^{2}\right)$ & 194 & 390 & 600 & 898 & 1749 \\
\hline Texture & Twill weave $2 / 2$ & Twill weave $2 / 2$ & Twill weave $2 / 2$ & - & - \\
\hline Yarn count (tex) & 68 & 272 & 224 & $\begin{array}{l}2400\left(0^{\circ}\right) \\
68\left(90^{\circ}\right)\end{array}$ & $\begin{array}{l}2400\left(0^{\circ}\right) \\
68\left(90^{\circ}\right)\end{array}$ \\
\hline Filament fineness $(\mu \mathrm{m})$ & 9 & $\begin{array}{l}13 \text { (weft) } \\
9 \text { (warp) }\end{array}$ & 8 & $17\left(0^{\circ}\right) 9\left(90^{\circ}\right)$ & $17\left(0^{\circ}\right) 9\left(90^{\circ}\right)$ \\
\hline Producer & HP-Textiles & HP-Textiles & AGK & Saertex & Saertex \\
\hline
\end{tabular}

E(electrical)-glass fibers as well as high strength S-glass fibers were used

be avoided due to the difference in electrochemical potential [3]. Through this technology, a slim, load-tolerant, and simple connection between the materials to be joined can be realized [4].

However, there are challenges in the implementation of fiber structures in aluminum die-cast components. The high melt speeds and high pressures occurring during mold filling require a reliable positioning and pre-tensioning of the fiber structures. Another challenge is a process-proof sealing, so that a part of the fiber structures can protrude from the aluminum area and serve as a connection to the CFRP structure.

With the help of a new high pressure die-casting tool, tensile samples of this joining technology could be realized. The design of the tool allows a reproducible positioning of the two-dimensional fiber halves at the center of the sample. For this purpose, an adapted gating system was developed that channels the melt in such a way that the fiber structures are positioned in the middle of the aluminum area. By means of a pre-tensioning system, the fibers can be prestressed outside the die-casting tool so that a constant fiber pre-tension is achieved before the casting process starts. By closing the mold halves of the die-casting tool, a portion of the glass fiber structure is sealed off from the melt so that the connection from the aluminum to the FRP can be achieved.

These so-called aluminum-glass fiber hybrid structures were evaluated with regard to their infiltration content ${ }^{1}$

\footnotetext{
1 Infiltration content: area of a cross section from a cast in fiber bundle that is infiltrated with aluminum in relation to the total cross section of the fiber bundle.
}

depending on the chosen casting parameters and textile parameters [5]. Hereby, these samples were characterized in terms of their achievable tensile strength and failure behavior. In addition to glass fiber fabrics with different grammage, unidirectional glass fibers were also integrated into the die-casting process and subsequently characterized in quasi-static tensile tests. To evaluate the results, reference samples made solely of GFRP, which had the same layer structure as the aluminum-GFRP hybrid structures, were used.

\section{Experimental}

\subsection{Manufacturing the samples}

The manufacture of the tensile samples has been described in previous experiments [5]. Various glass fiber textiles (see Table 1) with the appropriate layer structure were pre-tensed outside the high pressure die-casting tool.

With applied pre-tensions, the fibers were placed in the high pressure die casting tool. Through the closure of the mold halves, a part of the fiber structure is sealed off from the melt while the remainder is infiltrated with aluminum (AlSi10MnMg, melting temperature: approx. $720^{\circ} \mathrm{C}$ ) in the high pressure die-casting process (cold chamber diecasting: SC/N 66, Bühler GmbH, Uzwil, Switzerland; mold temperature: approx. $200{ }^{\circ} \mathrm{C}$; injection piston speed: $1.5 \mathrm{~m} / \mathrm{s}$, vacuum-assisted). In the next step the protruding side of the glass fibers was infiltrated with epoxy resin (resin: HACOPOL R131; hardener: HACOPOL H543, Hacotech GmbH, 


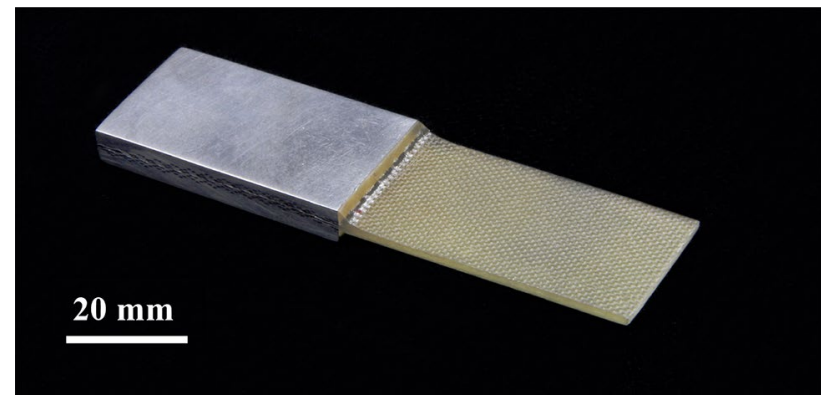

Fig. 1 Cut and finished tensile sample after the vacuum assisted infusion process

Table 2 Test series conducted on the partial infiltration of glass fiber textiles in the aluminum high pressure die-casting process with the glass fiber halves and holding pressures in the die casting process used

\begin{tabular}{|c|c|c|c|}
\hline Test series & Glass fiber blank & $\begin{array}{l}\text { Number } \\
\text { of stacked } \\
\text { layers }\end{array}$ & $\begin{array}{l}\text { Holding } \\
\text { pressure } \\
\text { (bar) }\end{array}$ \\
\hline TS1 & $194 \mathrm{~g} / \mathrm{m}^{2}$ fabric & 3 & 400 \\
\hline TS2 & $390 \mathrm{~g} / \mathrm{m}^{2}$ fabric & 3 & 400 \\
\hline TS3 & $600 \mathrm{~g} / \mathrm{m}^{2}$ fabric & 3 & 400 \\
\hline TS4 & $600 \mathrm{~g} / \mathrm{m}^{2}$ fabric & 3 & 500 \\
\hline TS5 & $600 \mathrm{~g} / \mathrm{m}^{2}$ fabric & 3 & 600 \\
\hline TS6 & $\begin{array}{l}600 \mathrm{~g} / \mathrm{m}^{2} \text { fabric } \\
\text { (Every second fiber bundle } \\
\text { across the direction of ten- } \\
\text { sile load removed) }\end{array}$ & 3 & 400 \\
\hline TS7 & $898 \mathrm{~g} / \mathrm{m}^{2}$ laying & 2 & 400 \\
\hline TS8 & $1749 \mathrm{~g} / \mathrm{m}^{2}$ laying & 1 & 400 \\
\hline
\end{tabular}

Hamburg, Germany; mixing ratio 100:32) in a vacuum assisted infusion process and subsequently cut into tensile samples using wet abrasive cutting (Brillant 265, ATM $\mathrm{GmbH}$, Mammelzen). From this, tensile samples with a width of $20 \mathrm{~mm}$ and a total length of $90 \mathrm{~mm}$ were manufactured (Fig. 1). The length of the aluminum area was $40 \mathrm{~mm}$ while the GFRP area was $50 \mathrm{~mm}$. Since the focus of this study was set on the joining of glass fibers and aluminum, carbon fibers were not included into mechanical testing.

\subsection{Experimental series}

An overview of all fiber textiles cast in the high pressure die-casting process and infiltrated with aluminum is given in Table 2. Six samples were made for each test series. In test series 1-3 the influence of the grammage of the glass fiber weave was investigated. In test series 3-5 the holding pressure was varied with constant grammage. In test series 6 the influence of a modification for optimization of the infiltration content was investigated by removing every

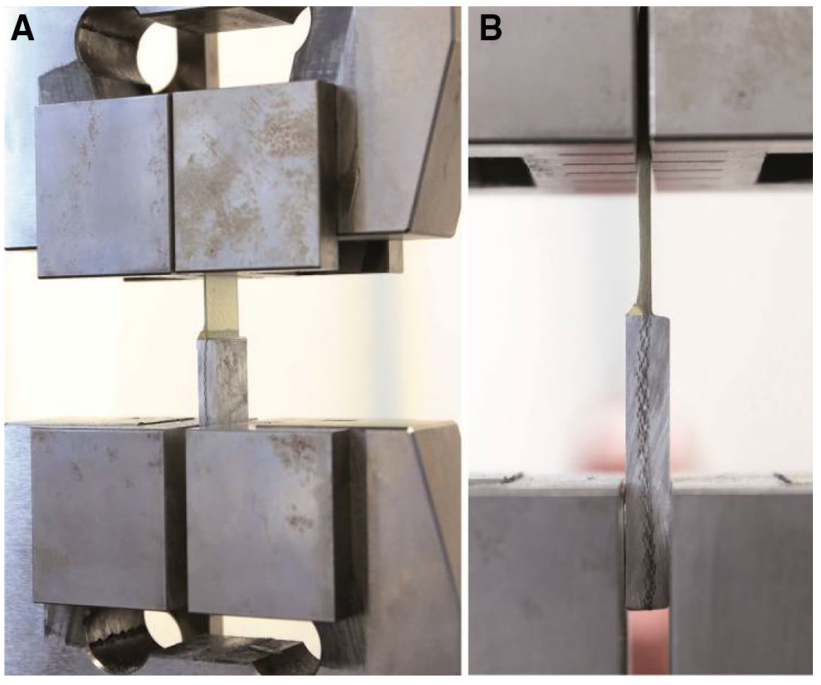

Fig. 2 Tensile tests of the aluminum-GFRP hybrid structures

second fiber bundle lateral to the direction of the tensile load. In test series 7 and 8 layings with different grammages were used. The different test series resulted in different total thicknesses of the layer structure. Through a variation of the bearing plates used in the transition area between the mold cavity and the tensioning system, the gap distance could be individually adjusted for each test series.

\subsection{Determination of the tensile strength}

The tensile tests were carried out following DIN EN 527-4 with a universal testing machine (Z020, Zwick Roell GmbH, Ulm, Germany) and a loading speed of $2 \mathrm{~mm} / \mathrm{min}$ (Fig. 2). The samples were clamped with wedge-shaped sample holders. A total clamping length of $50 \mathrm{~mm}$ was set. A preload of $10 \mathrm{~N}$ was applied. The maximum tensile force was obtained from the force-displacement data. To measure the cross-section the GFRP area was chosen, as for almost all samples the failure was observed in the GFRP area or in the aluminum near the transition between the materials. Therefore it was assumed that the thickness of the aluminum part has less influence on the strength and that the cross-section of the GFRP area is decisive. The elongation of the hybrid structures in the tensile test was determined using the traverse path. Therefore, no clear statement on the elongation state of the samples was possible, and thus calculations of the modulus of elasticity and elongation at break were not conducted.

In the tensile tests on the GFRP laying samples (TS7 und TS8) the maximum tensile force of the universal test machine of $20 \mathrm{kN}$ was exceeded. Therefore, the tensile tests were performed on a test machine that could withstand a higher tensile force (Z150, Zwick Roell GmbH, Ulm, Germany). 


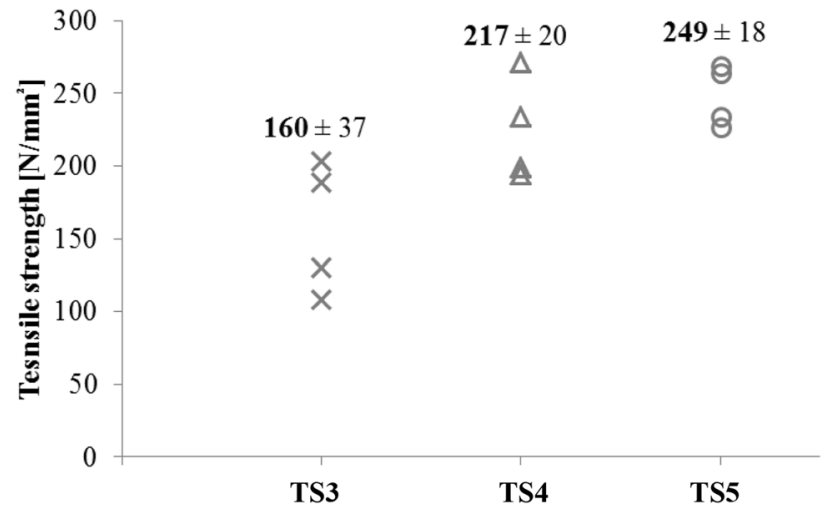

Fig. 3 Tensile strength of the aluminum-GFRP hybrid structures in dependence on the holding pressure during the high pressure diecasting of the fiber textiles. Shown are the individual measurements with median and MAD for $n=4$. For all test series, three layers of the $600 \mathrm{~g} / \mathrm{m}^{2}$ fabrics were used

The tensile tests were conducted on three to five samples, depending on the test series. For comparison, samples were made of pure GFRP and also tested.

\subsection{Analysis of the failure mechanisms}

An analysis of the failure mechanisms of the hybrid structures was first performed visually and the fracture phenomena observed were divided into different categories. Individual parts of the fractured areas of selected test series were examined in greater detail using a focused ion beam microscope (FIB).

A question during the analysis of the fracture areas was to what extent the aluminum adheres to the glass fibers after the fracture. For this, an energy-dispersive X-ray analysis (EDX) with an acceleration voltage of $10 \mathrm{kV}$ within an energy range of $20 \mathrm{keV}$ was also performed using a Silicon Drift Detector (SSD).

\section{Results and evaluation}

\subsection{Tensile strength depending on the holding pressure during the high pressure die-casting process}

Figure 3 shows the tensile strength dependent on the holding pressure used during the casting of the glass fiber textiles. While in previous experiments, depending on the high pressure die-casting tool, various dependencies between the infiltration content and the holding pressure could be observed [5, 6], in the present investigation the tensile strength increased with increasing holding pressure. At a holding pressure of 400 bar all tensile samples failed in the GFRP area just above the transition between the materials (Fig. 4a). At a holding pressure of 500 bar in two of the four samples the glass fibers fractured partially or completely within the aluminum and were extracted from it (Fig. 4b). Hereby, a thin layer of aluminum remained on the glass fiber halves. With a holding pressure of 600 bar this effect was observed for three of the four samples (Fig. 4c).

With increasing holding pressure a general change in the fracture behavior of the hybrid structures was observed. It can be assumed that a variety of factors played a role in this.

After casting the glass fiber halves and before the vacuum infusion, the pre-damage to the glass fiber halves was characterized for each sample (torn fiber bundles, visible mold imprint, discoloration of the glass fibers, etc.). The samples in test series 3, with a holding pressure of 400 bar, hereby demonstrated the greatest degree of damage, which led to the observed fracture behavior in the GRFP area. Hereby it could be assumed that this mechanical pre-damage to the fibers through the locking force in the tool is higher than the process-dependent thermal pre-damage of the fibers during the casting in the aluminum area.

The pre-damage is a factor that could explain the relatively low strength observed for test series 3. Apart from that, general relationship between holding pressure and strength can be observed, that needs further explanation.
TS3 (400 bar)

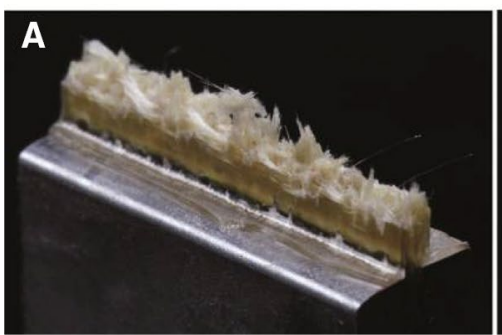

TS4 (500 bar)

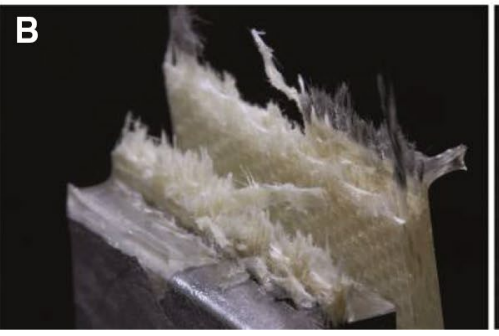

TS5 (600 bar)

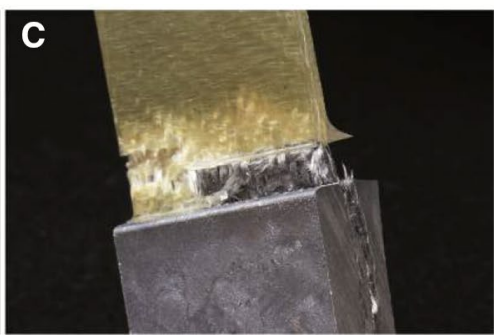

Fig. 4 Fracture areas of the aluminum-GFRP hybrid structures tested in the tensile tests in dependence on the holding pressure used during the casting of the fiber textiles in the high pressure die-casting process 


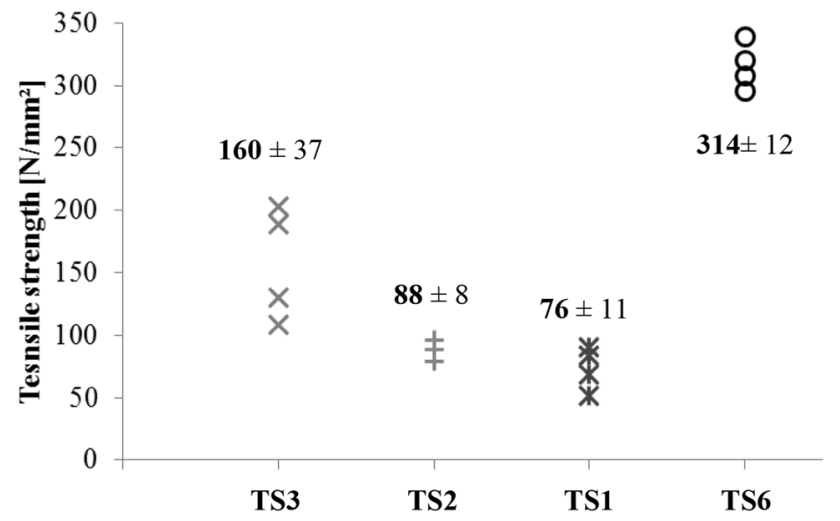

Fig. 5 Tensile strength of the aluminum-GFRP hybrid structures for different grammages of the cast-in fiber textiles. Shown are the individual measurements with the median and MAD for $n=4$ (test series 3,1 , and 6) and $n=3$ (test series 2)

Therefore, a closer look on the process and the moment where the holding pressure is applied is necessary. The holding pressure is applied for a short period of time during the solidification of the aluminum. During the solidification, it should be noted that the aluminum matrix has a higher thermal expansion compared to the glass fibers. Due to a higher thermal expansion of the aluminum compared to glass fibers, uneven shrinkage of the materials leads to mechanical clamping between glass fibers and aluminum [7]. Since there is no chemical bonding between the components [8], the interfacial shear strength depends on the coefficient of friction and the clamping tension [9]. Since the coefficient of friction can be assumed to be constant, the interfacial shear strength depends on the clamping tension. The clamping tension is caused by the shrinkage of the aluminum during solidification. A higher holding pressure during solidification adds to this pressure caused by shrinkage and leads to an even higher mechanical clamping and therefore interfacial shear strength after the solidification. This effect could explain higher strengths of hybrid structures in dependence on holding pressure during the high pressure die casting process. To validate this assumption, further experiments without the interfering effect of glass fiber pre-damage are necessary.

\subsection{Tensile strength in dependence of the grammage and the type of glass fiber}

Figure 5 shows the tensile strength in dependence on the grammage of the cast-in glass fiber fabric. For a better comparison, the results for test series 3, already shown in Fig. 4, are given again. The tensile strength for the glass fiber fabric with a grammage of 390 and $194 \mathrm{~g} / \mathrm{m}^{2}$ is clearly less than the tensile strength of the hybrid structures with three layers of the $600 \mathrm{~g} / \mathrm{m}^{2}$ fabric.
In previous experiments with other high pressure diecasting tools it was determined that a lower infiltration content similarly leads to a lower tensile strength. This would explain the lower tensile strengths for the samples with the $194 \mathrm{~g} / \mathrm{m}^{2}$ grammage, for which in this experiment the by far lowest infiltration content was measured [5]. At a grammage of $390 \mathrm{~g} / \mathrm{m}^{2}$, however, a higher infiltration content could be measured. Nevertheless, the tensile strength of the sample is very low.

For the test series compared in Fig. 5, different glass fiber types were also used. For test series 3, S-glass fibers were cast, and for test series 1 and 2, E-glass fibers were cast. This explains the lower tensile strengths for test series 1 and 2. The strength of S-glass fibers is, on average, almost double that of E-glass fibers [10].

Van der Auwera (2016) [6] determined that the working temperatures during the casting of the fiber halves have a clear influence on the strength of the fibers. Tensile tests on thermally stressed individual filaments showed a residual strength of $28-68 \%$. A decrease in strength could be observed for both the S-glass fibers as well as the E-glass fibers, but the S-glass fibers retain a higher residual strength. This finding leads to the assumption that both the higher temperature resilience of the S-glass fibers as well as their generally higher strength in comparison to the E-glass fibers, also in a thermally unstressed condition, lead to the comparatively higher tensile strengths seen in test series 3 .

Due to less fibre undulation in the load direction in test series 6 , stress can be transferred equally to the aluminum matrix. An indicator for this are the higher extracted lengths of the fibers (Fig. 6c) in comparison to those obtained in the other test series. Strongly curved fibers cause stress concentrations, which lead to a failure of the fibers. With the less strongly curved fibers, the stresses are transferred deeper into the aluminum matrix, thus leading to a larger interface between the fiber and the matrix for stress transfer. This results in a significantly higher tensile force in comparison to the samples from test series 3, which otherwise were made using the same manufacturing parameters. Similar tendencies have also been found in other studies [11].

Figure 6 shows the fractured surface of the samples from test series 1, 2, and 6. In all variations there was a fracture in the glass fibers within the aluminum area beneath the transition to the GFRP area. Only one sample of test series 1 failed with a fracture in the GFRP area. The broken fibers were pulled out of the aluminum.

\subsection{Tensile strength of unidirectionally laid structures}

The tensile strength of the hybrid structures with cast-in glass fiber layings with different grammages are shown in Fig. 7. The strength achieved with a one-layered structure 

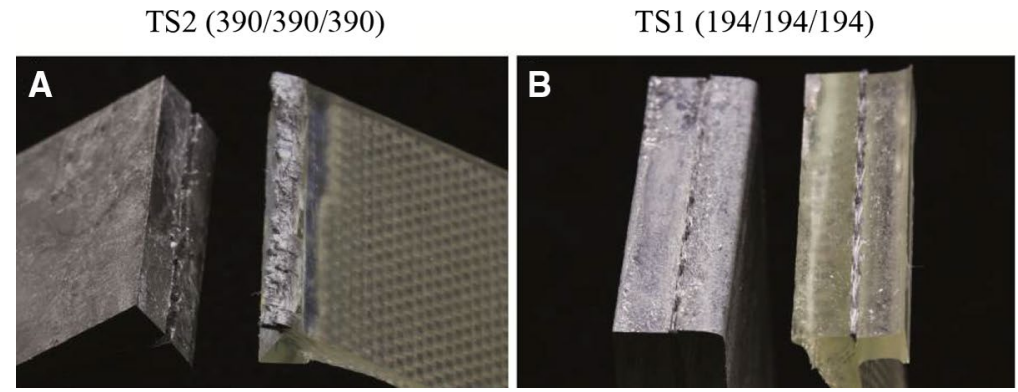

TS6 (600/600/600 modified)

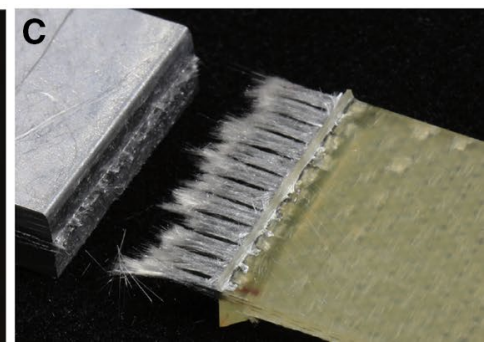

Fig. 6 Fracture areas of the aluminum-GFRP hybrid structures investigated using a tensile test for different grammages of the cast-in fabric (a and $\mathbf{b}$ ) as well as for a modification of the fiber structure (c). The fracture areas of the unmodified $600 \mathrm{~g} / \mathrm{m}^{2}$ fabrics (TS3) are shown in Fig. 4a

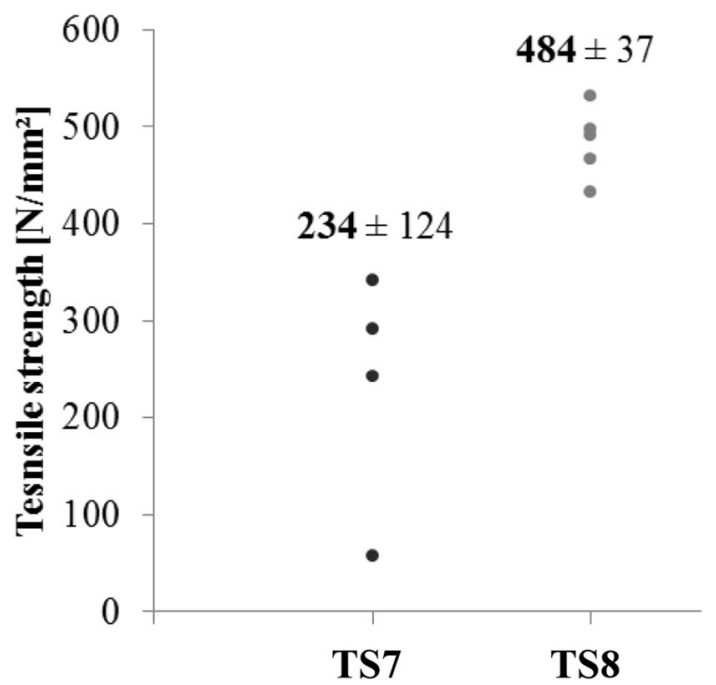

Fig. 7 Tensile strength of the aluminum-GFRP hybrid structures with cast-in glass fiber inserts with different grammages. While for the $1749 \mathrm{~g} / \mathrm{m}^{2}$ laying (test series 7) one layer was cast, for the $898 \mathrm{~g} / \mathrm{m}^{2}$ laying (test series 8) a two-layered structure was used, which represents a total grammage of $1796 \mathrm{~g} / \mathrm{m}^{2}$. Shown are the individual measurements with the median and MAD for $\mathrm{n}=4\left(898 \mathrm{~g} / \mathrm{m}^{2}\right)$ and $\mathrm{n}=5$ $\left(1749 \mathrm{~g} / \mathrm{m}^{2}\right)$

of the $1749 \mathrm{~g} / \mathrm{m}^{2}$ laying is more than twice as high in comparison to a two-layered structure of the $898 \mathrm{~g} / \mathrm{m}^{2}$ laying. Two of the samples of the $898 \mathrm{~g} / \mathrm{m}^{2}$ test series failed with a step-shaped fracture in the GFRP area (Fig. 8a). One of the samples failed with a step-shaped tear through the GFRP and the aluminum area (Fig. 8b). A further sample failed due to a splitting of the aluminum, whereby the glass fibers were extracted from the aluminum without any visible breakage of the aluminum. This final failure type was also observed in four of the five samples in the $1749 \mathrm{~g} / \mathrm{m}^{2}$ test series (Fig. 8c). A further sample failed due to a step-shaped tear through the GFRP and aluminum area (compare Fig. 8b).

The textile parameters of the laying are to a large extent identical (compare Table 1). The different grammages are achieved through different numbers of fibers in the direction of the thickness. The total grammage for the two-layered structure of the $898 \mathrm{~g} / \mathrm{m}^{2}$ laying is at $1796 \mathrm{~g} / \mathrm{m}^{2}$ almost identical to the grammage of the $1749 \mathrm{~g} / \mathrm{m}^{2}$ laying. Furthermore, for the $898 \mathrm{~g} / \mathrm{m}^{2}$ laying a higher infiltration length ${ }^{2}$, could be achieved [12], which indicates a higher infiltration content. In accordance with the assumption that a higher infiltration content leads to a higher tensile strength, for the $898 \mathrm{~g} /$ $\mathrm{m}^{2}$ laying a higher tensile strength of the hybrid structures would be expected. However, here too the opposite trend was observed, which in turn indicates that a higher infiltration content in the aluminum area does not necessarily lead to a higher tensile strength of a hybrid structure.

In the following, an approach is discussed that could explain the results for the tensile strengths in the test series with cast-in unidirectional layings. The infiltration of the glass fiber fabrics by aluminum is very low. A lower infiltration of the fiber bundles simultaneously means that less fibers are thermally damaged by the aluminum melt. At the same time, the lower infiltration content leads to the fact that during the vacuum infusion process of the fibers that extend from the aluminum the epoxy resin can enter the noninfiltrated interior parts of the fiber bundle (Fig. 9). Thus, the glass fibers are mostly infiltrated with epoxy resin, both in the GFRP area as well as the aluminum area.

Furthermore, in test series 7 the parts of the laying that were not infiltrated with aluminum were infiltrated with epoxy resin, similar to test series 8, as shown in Fig. 9. However, unlike in test series 8 there was no detachment of the infiltrated fibers at the interface to the surrounding aluminum matrix, rather there was a fracture of the fibers. An essential difference between the test series compared here is the infiltration length. For the $898 \mathrm{~g} / \mathrm{m}^{2}$ test series a greater infiltration length was determined, therefore, more fibers are enclosed by the aluminum matrix. This leads, on the one hand, to more fibers being thermally stressed. On the other hand, a higher proportion of tensile stress is transferred to the aluminum matrix. This could explain how most of the samples of the $898 \mathrm{~g} / \mathrm{m}^{2}$ test series failed due to a fracture

\footnotetext{
2 Infiltration length: depth of penetration of matrix material into a fiber bundle; measured from the outside of the single fiber bundle.
} 

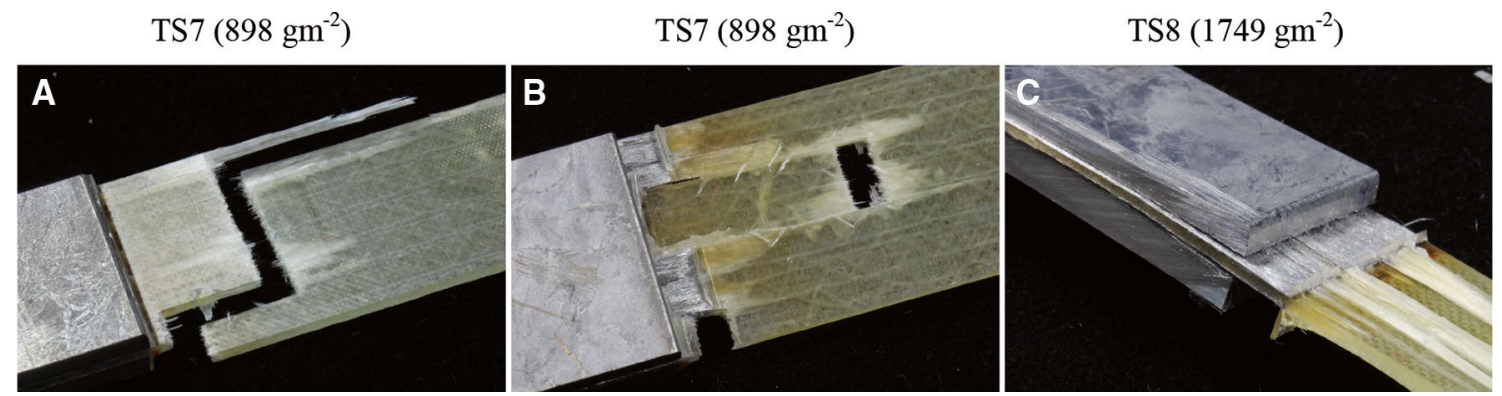

Fig. 8 Fracture areas of the aluminum-GFRP hybrid structures tested in the tensile tests for the unidirectional glass fiber layings with a grammage of $898 \mathrm{~g} / \mathrm{m}^{2}$ (test series 7, $\mathbf{a}$ and $\mathbf{b}$ ) and $1749 \mathrm{~g} / \mathrm{m}^{2}$ (test series $8, \mathbf{c}$ )

Fig. 9 a Overview of the fracture area of a sample investigated using a tensile test for test series 8 with a layer of the castin $1749 \mathrm{~g} / \mathrm{m}^{2}$ laying (compare Fig. 8c). b Microscopic detailed image for the section marked in (a)
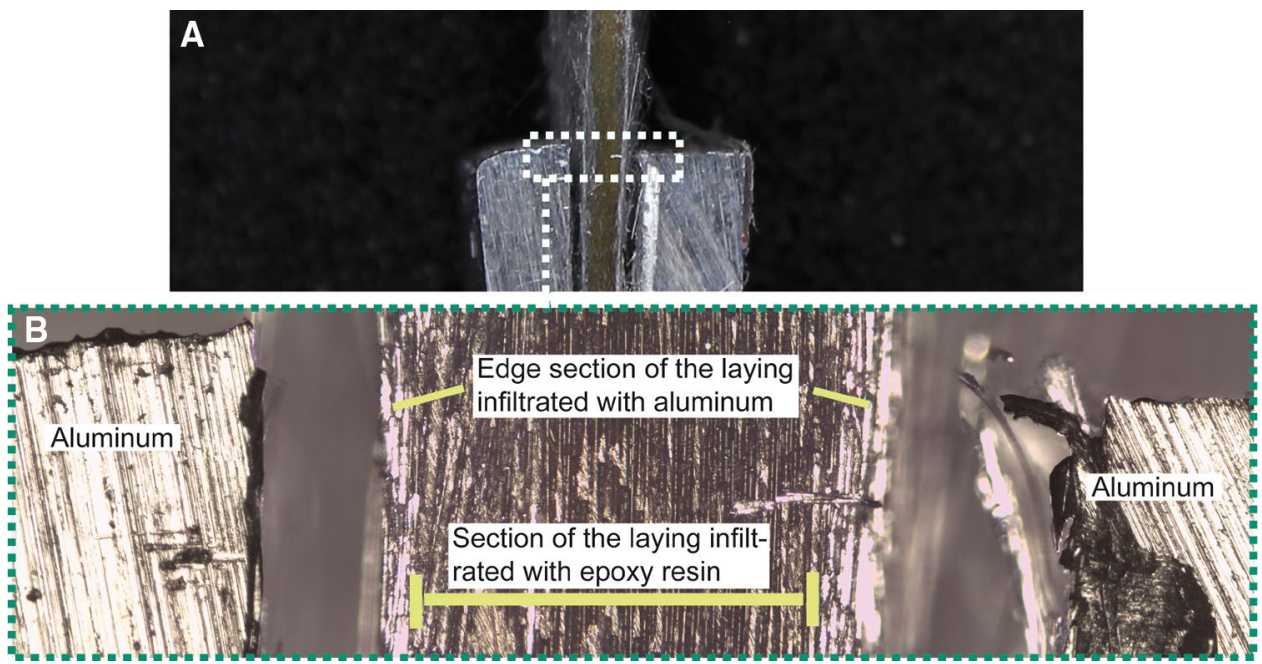

of the fibers. The thermal degradation has a considerable influence on the residual strength of the glass fibers (compare [13]). The crack initiation position during failure of the GFRP during tensile tests is mainly close to the transition region to aluminum for the test series 7 samples. Therefore, it can be assumed that a decrease in the fiber strength provides for the crack initiation there. With high probability, the thermal degradation is responsible for this decrease in strength of the glass fibers. For the $1749 \mathrm{~g} / \mathrm{m}^{2}$ test series a lower infiltration length was measured. Thus, less fibers were thermally pre-stressed and a lower proportion of the tension was transferred through the fibers onto the aluminum matrix. This led to a failure of the hybrid structures at the interface between the cast fibers and the surrounding aluminum (compare Fig. 9).

In test series 8 the forces or stresses leading to detachment are very high in comparison to those for the hybrid structures with cast-in fabrics. Hereby, it can be assumed that the clamping pressure induced by the clamping system in the tensile test has an influence on the obtained strength. As described above, the samples fail at the interface between the aluminum matrix and the glass fibers. The clamping system exerts a higher pressure, which impedes the pull-out or also the detachment of the glass fibers, which are mainly infiltrated by epoxy resin, from the aluminum. In order to exclude this effect, experiments regarding the clamping system should be considered in future.

A further important difference in comparison to the fabrics is that in the layings, all fibers run in the tensile direction. Layings generally have a lower degree of fiber curvature in comparison to glass fiber fabrics. In test series 6 it was shown that a lower fiber undulation has a positive influence on the tensile strength of the hybrid structures. This relationship was, however, observed for glass fiber fabric with a better infiltration in the aluminum area, which leads to other failure mechanisms. It would be interesting for future studies to cast glass fiber layings with lower grammages in order to increase the infiltration content of the fiber bundle and thus achieve a higher comparability with hybrid structures using cast-in fabric with regards to their failure mechanisms. 
Fig. 10 FIB images of the fracture area of a sample from test series 2
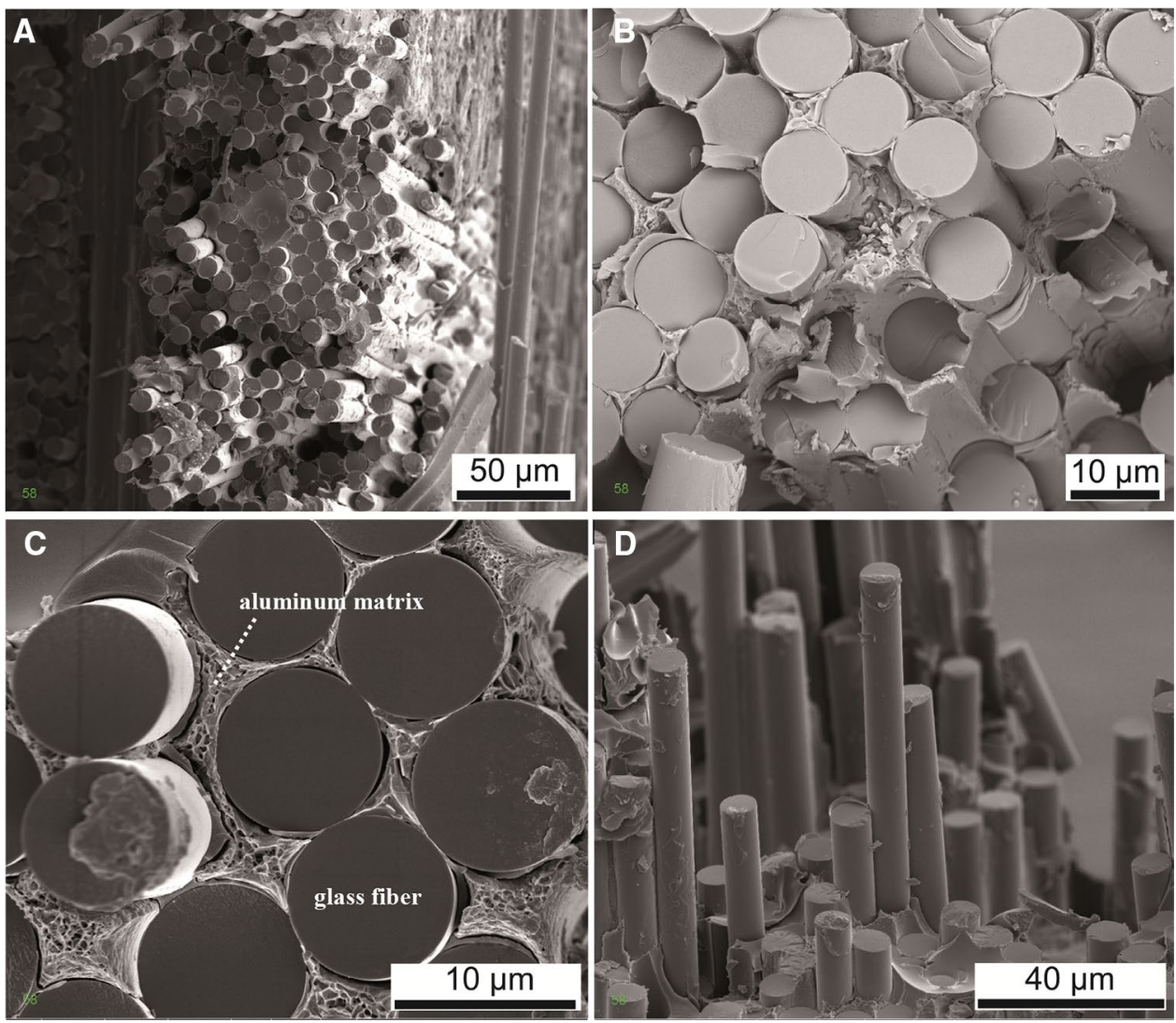

\subsection{Fracture area analysis using FIB and EDX}

Figure 10 shows the fracture areas of the tensile samples for test series 2 with a three-layered structure of the $390 \mathrm{~g} /$ $\mathrm{m}^{2}$ fabric. For this test series a relatively high infiltration content was measured in previous studies [5]. This could also be confirmed with an observation of the fracture areas. The interstices of the glass fibers appear to be almost completely filled with aluminum (Fig. 10c). During the failure of the hybrid structure, the fiber bundles were extracted from the aluminum area (Fig. 10a). Within the extracted fiber bundles, the fibers, which were broken relatively flush to the matrix, demonstrated a brittle fracture behavior. Individually, fibers that had been pulled out from the aluminum matrix were observed (Fig. 10d). At the fracture edges, a detachment of the aluminum from the glass fibers was observed (Fig. 10c). This, together with the lower adhesion of the pulled out fibers (Fig. 10d), indicates a lower fiber-matrix adhesion. At the same time, a brittle fracture behavior with shorter fiber extraction lengths is principally an indicator of a higher fiber-matrix adhesion in fiber composite materials (described in [14]).

As it was very difficult to determine whether the adhesions to the glass fibers consisted of aluminum, an EDX analysis was performed. The results are shown in Fig. 11. The detached matrix between the glass fibers was, as expected, aluminum (Fig. 11, green arrow). On the glass fibers, however, no adhesions of aluminum were observed. The light green discoloration of the fibers was caused by the bremsstrahlung and a low proportion of $\mathrm{Al}_{2} \mathrm{O}_{3}$ in the glass fibers.

This once more confirms the assumption that the fiber-matrix adhesion between the glass fibers and the surrounding aluminum matrix is not dominated by chemical or physical interactions at the interface, but rather by mechanical anchoring through the shrinkage of the aluminum.

An analysis of the fracture areas shows that the connection between the glass fibers and the aluminum matrix has a primarily mechanical origin. At the same time, a relationship between the infiltration content and the failure mechanism was observed.

\subsection{Categorization of the measured tensile strengths}

In order to be able to categorize the obtained results for the tensile strengths, reference samples $(n=6)$ were made of pure GFRP, which possessed the same layer structure as the samples cast in aluminum. The tensile strength of these samples were determined and the results are shown in Table 3.

Through a comparison of the strength of the aluminumGFRP hybrid structures manufactured within the framework 
Fig. 11 Results of the EDX analysis on the pulled out fibers at the fracture area of a sample from test series 2. a Overview image. b Occurrence of the element aluminum (green) in the left image
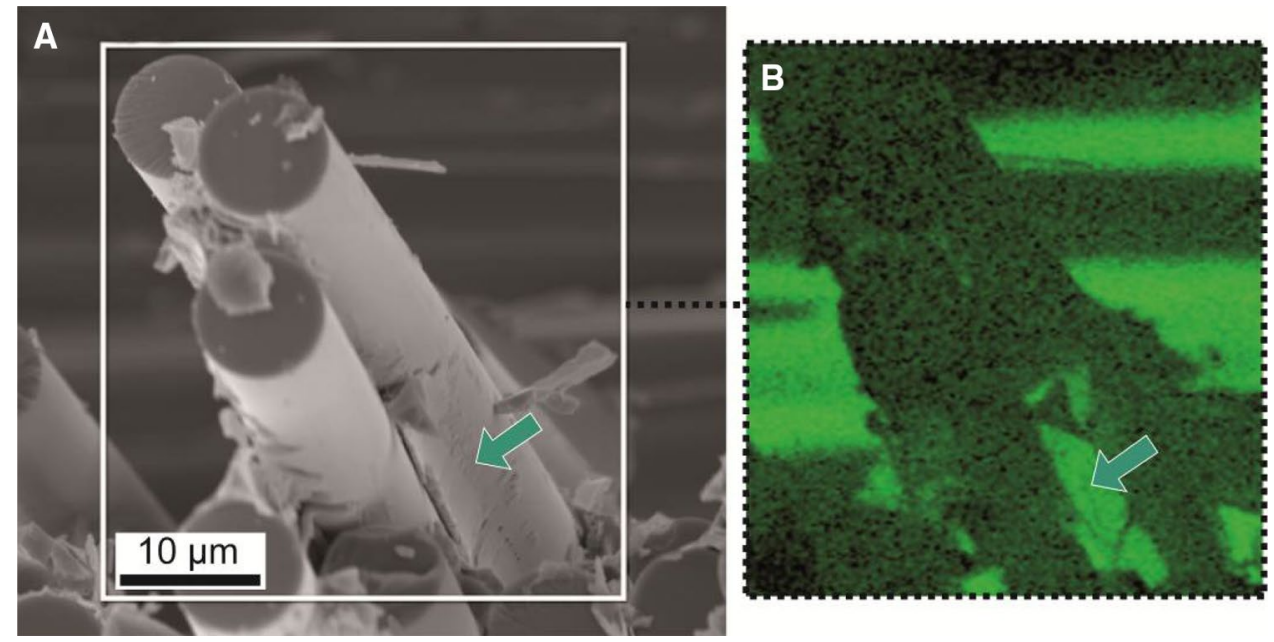

Table 3 Tensile strength of the GFRP reference samples; $\mathrm{n}=6$

\begin{tabular}{lll}
\hline Fiber blank & $\begin{array}{l}\text { Number of } \\
\text { layers }\end{array}$ & $\begin{array}{l}\text { Tensile strength in N/ } \\
\mathrm{mm}^{2} \text { (median } \pm \text { MAD) }\end{array}$ \\
\hline $194 \mathrm{~g} / \mathrm{m}^{2}$ fabric & 3 & $301 \pm 15$ \\
$390 \mathrm{~g} / \mathrm{m}^{2}$ fabric & 3 & $312 \pm 6$ \\
$600 \mathrm{~g} / \mathrm{m}^{2}$ fabric & 3 & $430 \pm 5$ \\
$898 \mathrm{~g} / \mathrm{m}^{2}$ UD-laying & 2 & $906 \pm 43$ \\
$1749 \mathrm{~g} / \mathrm{m}^{2}$ UD-laying & 1 & $951 \pm 33$ \\
\hline
\end{tabular}

of this study with the GFRP reference samples it becomes clear that in all test series there was a decrease in strength. Possible causes for this are manifold. The thermal damage to the fibers will play an essential role [6]. Furthermore, it can be assumed that mechanical interactions between the materials during the casting lead to damage at the microlevel, which reduces the strength of the hybrid structures. The highest strength for the glass fiber fabric was observed for test series 6, which had a lower thread thickness across the tensile direction. Hereby, $73 \%$ of the strength of the GFRP reference samples' strength was achieved. For the laying with a grammage of $1749 \mathrm{~g} / \mathrm{m}^{2}$, a tensile strength of $52 \%$ in comparison to the GFRP reference samples was achieved.

In addition to the comparison of the tensile strength obtained for the hybrid structures with those for the GFRP reference samples, a characterization regarding the strength of the aluminum is also of use. The strength of the used aluminum alloy $\mathrm{SF} 36$ ( $\mathrm{AlSi} 10 \mathrm{MnMg}$ ) in an as-cast state is, according to the manufacturer, 250-290 N/mm² [15], which lies beneath the strength of all GFRP reference samples tested in this study. In order to completely cast the glass fiber textiles in the aluminum, the manufactured aluminumGFRP hybrid structures were thicker in the aluminum part than in the GFRP part. Thus a comparison of the strengths of the hybrid structures with that of the aluminum is of less importance, as due to the greater size of the cross-section large forces can be taken in by the aluminum area, and none of the tested samples showed a fracture in the aluminum part. Nevertheless, it should be noted that the strength of the aluminum was exceeded in test series 6 for hybrid structures with cast-in fabric and in test series 8 for hybrid structures with cast-in layings. Through the increase of the holding pressure to $600 \mathrm{bar}$, also in test series 5 a comparable strength was achieved.

If the samples are reworked in the aluminum area and are, for example, ground down to the same thickness as the GFRP area, then the aluminum would be, due to the lower strength, a better partner for a comparison with the GFRP. As the strength of the hybrid structures examined in this study partially lies above that of the aluminum, for these variants no weakening of the whole system during the joining process through casting is assumed.

\section{Summary}

No relationship was determined between the infiltration content and the tensile strength of the hybrid structures. The tensile strength of the hybrid structures was positively influenced by a higher holding pressure during the high pressure die-casting process, the use of S-glass fibers, and less undulations of the glass fibers in the tensile direction. In addition, for hybrid structures with a lower infiltration content a higher strength could be achieved through a re-infiltration with epoxy resin.

The obtained tensile strengths achieved up to $73 \%$ of the strength of the GFRP structures and were in part above the strength of the aluminum. In comparison to the sample manufacture using the previous mold tool inserts, a twofold increase in the maximum tensile force was achieved. Through a variation in the holding pressure, a further 
increase in tensile strength is expected. Due to these findings, it can be assumed that the process used here enables the manufacture of integrated transition structures between the light-weight materials aluminum and GFRP without significant loss of strength.

Open Access This article is distributed under the terms of the Creative Commons Attribution 4.0 International License (http://creativeco mmons.org/licenses/by/4.0/), which permits unrestricted use, distribution, and reproduction in any medium, provided you give appropriate credit to the original author(s) and the source, provide a link to the Creative Commons license, and indicate if changes were made.

\section{References}

1. Denonville J (2015) Eine neue materialgerechte Fügetechnologie für uni-direktionale Faser-Kunststoff-Verbundwerkstoffe mit Glasund Carbonfasern. Dissertation, Stuttgart

2. Lang A, Husemann L, Herrmann AS (2013) Influence of textile process parameter on joint strength for integral CFRP-aluminum transition structures. Procedia Mater Sci 2:212-219

3. Wang WX, Takao Y, Matsubara T (2007) Galvanic corrosionresistant carbon fiber metal laminates. 16th International Conference on Composite Materials, Japan

4. Schiebel P, Lang A, Herrmann AS, Schimanski K, von Hehl A, Bomas H, Zoch H-W (2011) Bauweisen für CFK-AluminiumÜbergangsstrukturen im Leichtbau. Werkstoffe und werkstofftechnische Anwendungen, vol 41, Chemnitz, pp 393-398

5. Clausen J, Kelch M, Wöstmann F-J, Busse M (2017) Development of a high pressure die casting tool for partial integration of glass fiber structures. Key Eng Mater 742:520-526
6. Van der Auwera R et al (2014) Joining of Aluminium and CFRP Parts using glass fibres as transition elements. Euro Hybrid Materials and Structures, Stade, Presentation

7. Ballmes H (2013) Aluminiummatrix-Faserverbundwerkstoffe im Druckgießprozess-Verfahrens-grundlagen und Produkteigenschaften. Dissertation, Nuremberg

8. Li J-G (1994) Wetting of ceramic materials by liquid silicon, aluminium and metallic melts containing titanium and other reactive elements: a review, vol 20, Ceramics International, pp 391-412

9. Chawla N, Chawla KK (2006) Metal matrix composites. Springer Science \& Business Media, New York

10. Schürmann H (2007) Konstruieren mit Faser-Kunststoff-Verbunden. 2. Aufl. Springer-Verlag, New York

11. Kunze A, Clausen J, Van der Auwera R, von Hehl A, Zoch H-W, Busse M (2016) Influence of material parameters on the tensile force of integral Aluminum CFRP Hybrid Structures fabricated by casting technology. Proceedings Euro Hybrid-Materials and Structures, Kaiserslautern, pp 30-35

12. Clausen J, Van der Auwera R, Wöstmann F-J, Schmid A (2015) Integration textiler Strukturen in den Aluminium-Druckguss zur Realisierung integraler CFK-Aluminium-Verbindungen. Conference Proceedings 7. Landshuter Leichtbau-Colloquium, Landshut, pp. 197-207

13. Thomason JL, Ure J, Yang L, Kao CC (2012) Mechanical study on surface treated Glass Fibres after thermal conditioning. Conference Proceedings 15th European Conference on Composite Materials, Venice,

14. Figueiredo JL, Bernardo CA, Baker RT, Hüttinger KJ (2013): Carbon fibers filaments and composites. Springer Science \& Business Media, New York

15. Rheinfelden GmbH (2003) Hüttenaluminium Gusslegierungen, Ausgabe 6. 3.Auflage. Rheinfelden 